\title{
Analisa Pemilihan Material pada Bangunan Gudang Atag di Desa Karanganyar Kabupaten Jember
}

\section{Chen Ie Chin}

Program Studi Desain Interior, Universitas Kristen Petra, Surabaya

cheniechinn@yahoo.com

\begin{abstract}
ABSTRAK
Kabupaten Jember dan perkebunan tembakau merupakan dua hal yang tidak terpisahkan. Tembakau telah menjadi komoditas ekspor terkenal di Jember. Kabupaten Jember merupakan salah satu dari tiga wilayah penghasil tembakau jenis na-oogst di Indonesia. Tembakau na-oogst yang merupakan bahan dasar pembuatan cerutu ini melalui proses pengeringan yang berbeda dengan tembakau jenis lain, sehingga memerlukan tempat pengeringan, kondisi, dan perlakuan yang berbeda pula. Tembakau berjenis na-oogst biasanya dikeringkan dengan bantuan gudang pengeringan atau yang biasa disebut dengan gudang atag sehingga pada wilayah-wilayah penghasil tembakau na-oogst biasanya kerap dijumpai bangunan gudang ini. Gudang yang memiliki fungsi utama sebagai tempat mengeringkan tembakau ini dibangun dengan material-material yang mendukung fungsinya. Tujuan dari penelitian ini adalah untuk membahas dan memberi pengertian lebih mendalam kepada masyarakat berkenaan dengan pertimbangan dalam pemilihan material pembentuk gudang atag, termasuk didalamnya kekurangan dan kelebihan dari masing-masing material. Material pembentuk gudang atag menjadi fokus dalam tulisan ini karena perannya yang sangat signifikan terhadap keberhasilan proses pengeringan dan mutu tembakau yang dihasilkan serta dampaknya bagi lingkungan alam dan manusia.
\end{abstract}

Kata kunci: Tembakau; Material; Gudang Atag; Jember

\section{ABSTRACT}

Jember Regency and tobacco plantations are two inseparable things. Tobacco has become a wellknown export commodity in Jember. Jember Regency is one of the three regions in Indonesia that produce na-oogst tobacco. Na-oogst tobacco, which is the main ingredient for cigars manufacture, goes through a different drying process from other types of tobacco, so it requires different drying place, conditions, and treatments. Na-oogst tobacco is usually dried with the help of a drying tobacco barn or commonly known as gudang atag, so in areas that produce this type of tobacco, buildings like these are often found. Gudang atag, which has the main function as a place to dry tobacco, was built with materials that support its function. The purpose of this study is to discuss and provide a deeper understanding to the public regarding considerations in the selection of materials that form gudang atag, which include the advantages and disadvantages of each material that are being used. Materials that form gudang atag is the main focus of this paper because of its very significant role in the success of the drying process and the quality of the tobacco produced also its impact on human and environment. Keywords: Tobacco; Material; Gudang Atag; Jember

\section{PENDAHULUAN}

Indonesia merupakan negara dengan tanah yang subur dan sumber daya alam yang melimpah. Karena tanah Indonesia yang mashur inilah maka melalui kolonialisme Barat sekitar awal abad ke - 17 tanaman tembakau mulai dibudidayakan di tanah Indonesia. Menurut Padmo (1994), Belanda mendirikan perkebunan dan pabrik tembakau di tiga wilayah Indonesia yang diawali di Deli dengan sebutan Vereenigde Deli Maatschappij (VDM). Kemudian pada pertengahan abad ke - 18 pembudidayaan tembakau merambah ke Jember Karesidenan Besuki, Jawa Timur. Pabrik dan perkebunan milik Belanda di Jember kemudian disebut Landbouw Maatschappij Oud-Djember (LMOD) dan selanjutnya didirikanlah di Kabupaten Klaten Karesidenan Surakarta dengan nama NV. Klatensche Cultuurmaatschappij atau NV. KCM. Ketiga wilayah tersebut yang kemudian hingga saat ini menjadi penghasil tembakau bahan cerutu yang merupakan salah satu komoditas ekspor terkenal Indonesia dan menghantarkan 
Indonesia menjadi penghasil cerutu terbesar kedua di dunia setelah Kuba. Di Jember sendiri selain berdampak pada pertumbuhan ekonomi, usaha tembakau juga berpengaruh pada perkembangan demografi dan kultur. Pada tahun 1883 Jember berkembang menjadi regentschap terpisah dari Bondowoso beriringan dengan didirikannya berbagai sarana dan infrastruktur di Jember untuk kepentingan usaha tembakau. Setelah Indonesia merdeka, berdasarkan undang-undang No. 86 tahun 1958 dan Peraturan Pemerintah No. 4 tahun 1959 kemudian perusahaan dan perkebunan tembakau milik Belanda di nasionaisasi dan saat ini dikenal sebagai PT Perkebunan Nusantara X (PTPN X). Ketenaran hasil kebun tembakau Jember mulai awal masuknya hingga saat ini tidak pernah meredup. Sektor perkebunan tembakau telah menjadi penopang perekonomian daerah Jember. Data BPS tahun 2017 mencatat bahwa $57,5 \%$ penghasilan asli daerah Jember bersumber dari perkebunan tembakau yang $90 \%$ hasilnya di ekspor ke mancanegara.

Seiring dengan pembangunan yang dilakukan Belanda, masyarakat Indonesia secara tidak langsung juga mulai diperkenalkan dengan teknik pengeringan tembakau menggunakan gudang pengeringan tembakau atau yang biasa disebut dengan gudang atag atau los. Gudang atag telah menjadi ciri khas daerah penghasil tembakau cerutu. Meskipun gudang atag telah menjadi elemen yang tak terpisahkan dengan sektor perkebunan tembakau cerutu namun masih banyak orang yang asing terhadap bangunan ini bahkan mengira bahwa gudang atag adalah rumah adat setempat. Hal ini tentunya tidak mengherankan mengingat tampilan gudang atag yang sangat tradisional dan menggunakan material-material alami sebagai elemen penyusunnya. Di tengah jaman dan teknologi yang semakin berkembang, tampilan dan pemilihan material dari gudang atag sendiri masih tetap sama seperti sedia kala. Walau dengan tampilan yang telah dimakan jaman serta pemilihan material yang sudah dianggap kuno dan mulai ditinggalkan dalam arsitektur modern, gudang atag tetap mampu menjalankan fungsinya dengan baik sebagaimana mestinya. Gudang atag yang masih eksis dan digunakan hingga saat ini cukup membuktikan bahwa fungsi gudang atag sebagai tempat pengeringan tembakau masih belum tergantikan.

Terdapat beberapa elemen penting dalam proses pengeringan tembakau berbasis air curing dengan bantuan gudang atag, diantaranya adalah material pembungkus gudang atag, ukuran gudang atag, angin, dan pekerja atau tenaga manusia (Citraningrum dan Herawati, 2019). Pada penelitian ini penulis tertarik untuk meneliti lebih dalam alasan dibalik pemilihan material dari gudang atag dan mengapa gudang atag pada masa kini tetap mempertahankan penggunaan material alami yang memiliki beberapa kekurangan serta terkesan kurang modern. Beberapa material dari gudang atag bahkan terbilang kurang aman karena rawan terhadap bencana kebakaran. Dalam melaksanakan penelitian ini dipilihlah objek gudang atag yang berada di desa Karanganyar kecamatan Ambulu kabupaten Jember. Gudang atag yang akan menjadi objek utama penelitian ini digunakan untuk membantu proses pengeringan tembakau dengan teknik pengasapan.

\section{METODE PENELITIAN}

Penelitian ini menggunakan metode penelitan deskriptif dengan pendekatan kualitatif. Penelitian deskriptif kualitatif merupakan penelitian yang memiliki tujuan untuk memberi gambaran dan mendeskripsikan suatu peristiwa atau fenomena yang terjadi di lapangan serta menyajikan data secara akurat, sistematis, dan faktual mengenai fakta atau fenomena di lapangan (Moloeng:2007). Penelitian deskriptif kualitatif ini bertujuan untuk memperoleh gambaran dan membahas lebih dalam mengenai salah satu aspek penting dari gudang atag yang sangat berpengaruh dalam proses pengeringan dan mutu tembakau yang dihasilkan yakni pemilihan material pembentuk gudang atag beserta pertimbangan - pertimbangan yang ada berkenaan dengan dipilihnya material terentu. Adapun penelitian dan proses analisa data 
mengenai studi kasus Pemilihan Material pada Elemen Interior Gudang Atag di Desa Karanganyar Kabupaten Jember menggunakan beberapa metode pengumpulan data dan analisa sebagai berikut.

\section{A. Metode Pengumpulan Data}

1. Pengumpulan Data Primer

Data primer merupakan data utama yang diperoleh langsung dari sumber. Data primer pada penelitian ini diperoleh dengan mengamati secara langsung gudang atag di desa karanganyar kabupaten Jember dan melakukan wawancara dengan pekerja gudang atag tersebut.

- Observasi

Dalam proses pengumpulan data, penelitian ini menggunakan teknik observasi yang merupakan teknik atau metode pengumpulan data dimana peneliti mengamati dan mendata informasi yang ada sesuai dengan fakta di lapangan (Gulo dan Hardiwati, 2002). Dalam penelitian ini dilakukan observasi terhadap material penyusun bangunan gudang atag khususnya material dari elemen interiornya. Dokumentasi lapangan dari objek penelitian juga dilakukan selama proses observasi lapangan berlangsung.

- Wawancara

Bentuk wawancara yang peneliti gunakan adalah wawancara terbuka dengan beberapa informan yang merupakan pekerja renovasi dari gudang atag di desa Karanganyar kabupaten Jember yang menjadi objek utama pada penelitian ini. Jenis wawancara tak terstruktur bersifat luwes dimana susunan kata dan pertanyaan dapat diubah seiring jalannya wawancara disesuaikan dengan kebutuhan dan kondisi (Mulyana, 2004). Wawancara ini bertujuan untuk mengumpulkan data dan memahami pandangan informan yang berperan sebagai pekerja renovasi gudang atag dan masyarakat setempat terhadap pemilihan material gudang atag di desa Karanganyar kabupaten jember.

2. Pengumpulan Data Sekunder

Data sekunder merupakan data yang tidak diperoleh secara langsung dari sumber aslinya. Data sekunder pada penelitian ini diperoleh melalui studi literatur berupa jurnal ilmiah, $e$-book, dan website resmi berkenaan dengan gudang atag dan material penyusunnya. Literatur memiliki peran penting dalam perumusan masalah dan menjadi dasar bagi peneliti dalam usaha pemahaman suatu masalah (Nugrahani, 2014).

\section{B. Metode Analisa Data}

Setelah data primer maupun sekunder telah terkumpul dengan lengkap maka kemudian dilakukan analisa terhadap data-data tersebut. Penelitian ini menggunakan metode deskriptif kualitatif dalam proses analisa data. Teknik analisis deskriptif kualitatif merupakan teknik menganalisis, menggambarkan, dan meringkas berbagai situasi serta kondisi dari data yang terkumpul. Adapun hasil analisa yang didapatkan berupa deskripsi yang dijabarkan melalui tulisan.

\section{HASIL PENELITIAN DAN PEMBAHASAN}

Gudang atag yang menjadi objek pada penelitian ini merupakan salah satu gudang atag di wilayah desa Karanganyar, Kecamatan Ambulu, Kabupaten Jember. Gudang memanjang sejajar dari utara ke selatan dan tegak lurus dengan timur dan barat. 


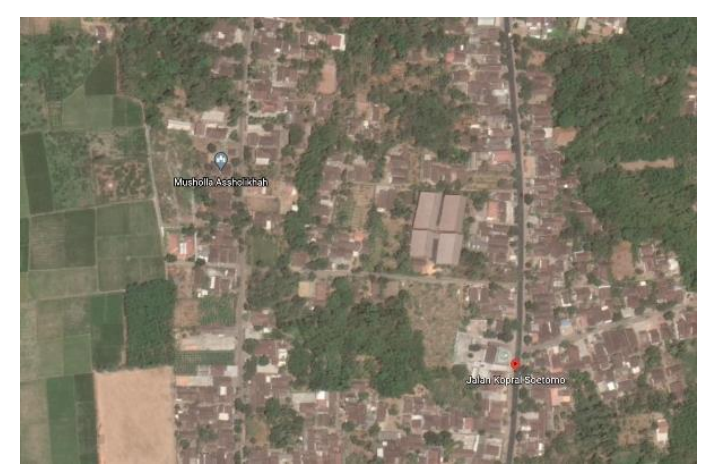

Gambar 1. Lokasi objek penelitian Sumber: Google Earth (2021)

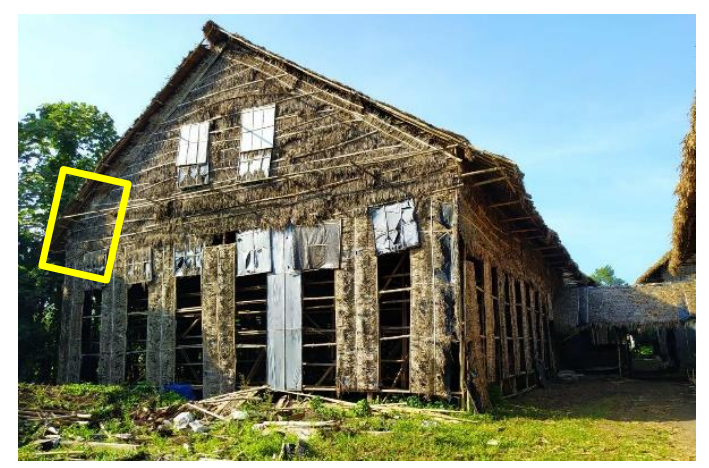

Gambar 2. Tampak luar Gudang Atag Sumber: Dokumentasi Penulis (2021)

Dalam setahun gudang atag ini dipakai dua kali selama kurang lebih 20 hari tiap periode pemakaiannya. Saat akan digunakan biasanya dilakukan renovasi untuk memperbaiki bagian yang rusak atau mengganti material yang sudah lama. Adapun material-material penyusun dari gudang atag di desa Karanganyar kabupaten Jember ini adalah sebagai berikut.

\section{A. Material Atap, Dinding, dan Jendela}

Atap, dinding, dan jendela dari gudang atag terbuat dari susunan rapat daun tebu kering yang ditali dengan tali bambu. Opsi lain sebagai pengganti dari daun tebu kering adalah jerami dan daun bambu kering, namun material daun tebu kering lebih banyak dijumpai penggunaannya.

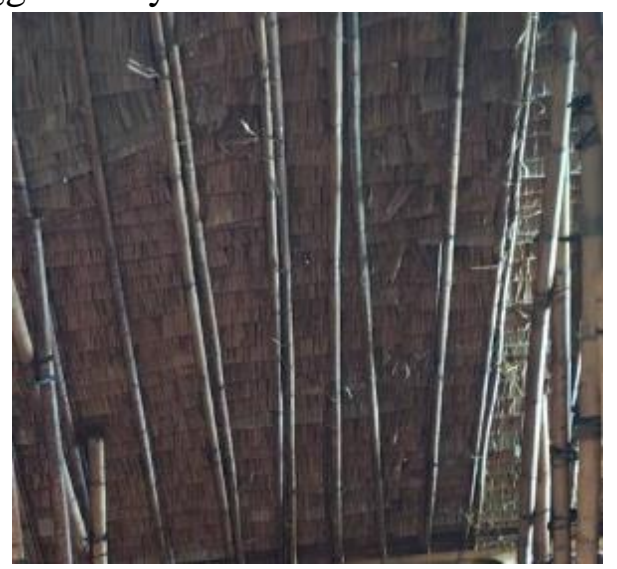

Gambar 3. Material Atap Gudang Atag tampak dalam

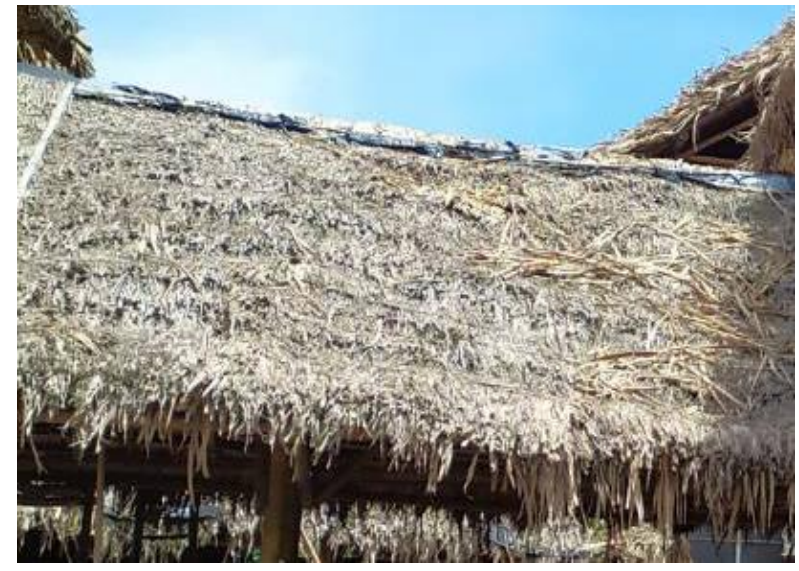

Gambar 4. Material Atap Gudang Atag tampak luar

1. Daun Tebu Kering

Berdasarkan observasi, wawancara dan studi literatur yang telah dilakukan maka ditemukan alasan dan kelebihan dari penggunaan anyaman daun tebu kering sebagai elemen penyusun atap, dinding, dan jendela dari gudang atag adalah sebagai berikut:

- Ringan, anyaman daun tebu kering tergolong ringan apabila dibandingkan dengan material atap lainnya. Beratnya yang ringan membuat atap dari anyaman daun tebu kering tidak terlalu membebani struktur gudang atag sehingga tidak mudah roboh.

- Memiliki celah-celah yang membantu gudang atag untuk menstabilkan suhu dan kelembaban di dalamnya. Anyaman daun tebu kering yang disusun dapat meghalau air hujan dan sinar matahari langsung masuk ke dalam gudang namun tetap memberi celah bagi asap saat proses pengovenan tembakau untuk bersirkulasi ke luar secara perlahan. 
- Anyaman daun tebu kering dapat menyerap kelembaban berlebih di dalam gudang atag.

- Mudah direnovasi apabila terdapat kerusakan.

- Daun tebu kering merupakan material alami yang berlimpah kauntitasnya, ramah lingkungan, dan sangat mudah ditemukan di wilayah sekitar Jember dengan harga yang tentunya sangat terjangkau kisaran 5.000 hingga 10.000 rupiah per meternya.

- Penggunaan daun tebu kering sebagai material gudang atag juga membawa dampak positif bagi masyarakat sekitar karena dapat menjadi peluang usaha.

- Menambah nilai vernkularitas dari bangunan gudang atag.

Selain beragam kelebihan yang menjadi alasan dipilihnya material anyaman daun tebu kering sebagai elemen dari atap, dinding, dan jendela gudang atag material ini juga memiliki beberapa kekurangan sebagai berikut:

- Mudah terbakar, daun tebu kering merupakan material yang sangat mudah tersulut api mengingat kadar airnya yang minim. Material ini lah yang seringkali mempercepat rambatan api dan memperparah bencana kebakaran yang kerap kali menimpa gudanggudang atag.

- Tidak tahan lama, anyaman daun tebu kering biasanya hanya bertahan sekitar satu setengah tahun saja dan harus sering diganti agar fungsinya berjalan dengan baik. Hal ini merupakan hal yang wajar mengingat material daun tebu kering merupakan material alami yang akan dengan mudah terurai oleh alam. Durasi ketahanan anayaman daun tebu kering yang singkat sebenarnya tidak terlalu berpengaruh mengingat gudang atag ini hanya digunakan pada periode-periode tertentu dalam waktu yang singkat pula serta sifat dari bangunan gudang atag yang tidak permanen.

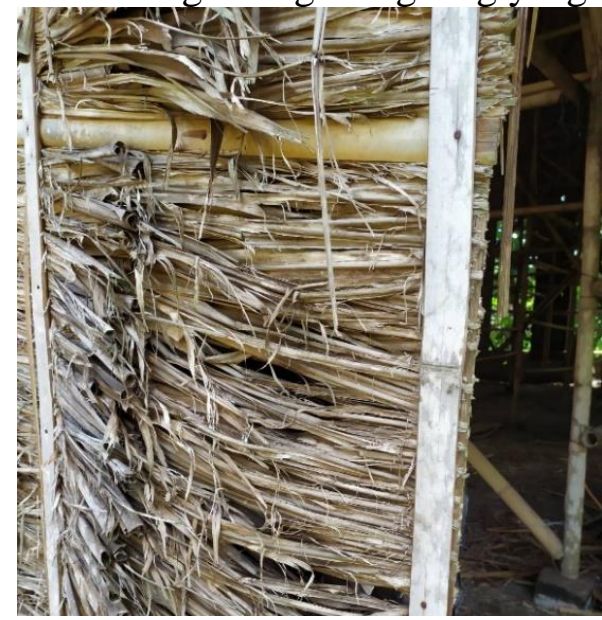

Gambaar 5. Material Dinding Gudang Atag tampak luar

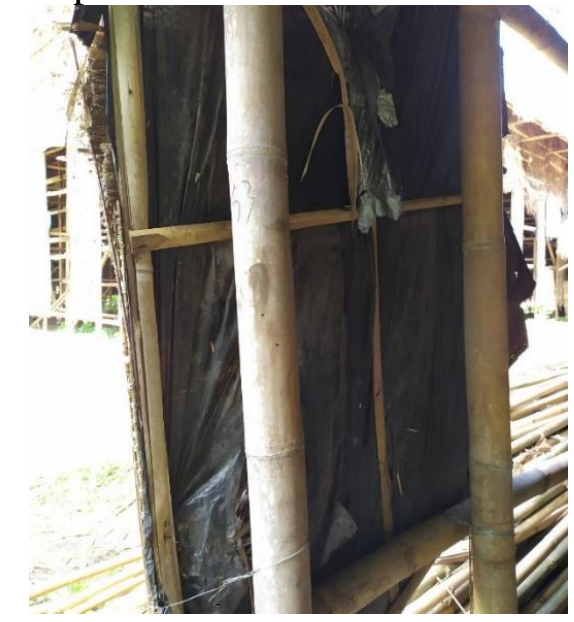

Gambar 6. Material Dinding Gudang Atag tampak dalam

\section{2. $\quad$ Plastic Sheeting}

Sama seperti atapnya, dinding dan jendela gudang atag ini juga terbuat dari anyaman daun tebu kering. Namun, yang membedakan adalah lapisan plastik di balik anyaman daun tebu kering tersebut. Adapun alasan dan kelebihan dari penambahan lapisan plastik pada dinding dan jendela gudang atag adalah sebagai berikut.

- Material plastik dapat mengunci panas di dalam gudang dan mempertahankan suhu. Lapisan plastik yang ditambahkan pada dinding anyaman tebu kering dapat mempertahankan suhu panas di dalam gudang saat hujan dan menahan panas berlebih 
dari luar gudang saat cuaca sedang terik sehingga suhu di dalam gudang menjadi relatif stabil.

- Penggunaan material plastik ini juga merupakan upaya untuk menekan biaya pembangunan gudang atag karena harganya yang sangat terjangkau. Dengan menambahkan lapisan plastik pada dinding dan jendela gudang atag maka anyaman daun tebu kering yang diperlukan akan berkurang pula.

Adapun kekurangan dari material plastic sheeting pada dinding dan jendela gudang atag di desa Karanganyar ini adalah sebagai berikut.

- Material plastik merupakan material yang kurang ramah lingkungan mengingat gudang atag akan direnovasi secara berkala setiap akan digunakan sehingga sangat berpotensi menimbulkan penumpukan limbah plastik. Terlihat di area sekitar gudang atag yang menjadi objek penelitian ini terdapat tumpukan limbah plastik yang diperkirakan merupakan sisa-sisa material dari renovasi sebelumnya.

Material seng yang biasa digunakan pada atap gudang pengeringan tembakau di Amerika dipercaya membuat suhu di dalam gudang menjadi terlalu panas apabila diterapkan pada gudang atag di Indonesia. Dalam Saraswati (2013) juga disebutkan bahwa pernah dilakukan upaya mengganti material atap gudang atag di wilayah Jember menjadi terpal, walaupun warna daun yang dihasilkan lebih baik namun tembakau yang dihasilkan memiliki aroma yang berbeda. Dikarenakan kelebihan yang didapat lebih banyak jika dibanding dengan kekurangannya, hingga saat ini material atap, dinding, dan jendela dari gudang atag yang menjadi standar tetaplah material daun tebu kering atau sejenisnya dan tambahan lapisan plastik untuk dinding serta jendela. Hal ini juga didukung dengan belum ditemukannya alternatif material yang cocok untuk menggantikan anyaman daun tebu kering dan plastik.

\section{B. Material Struktur}

Berdasarkan hasil observasi, struktur kolom dan rangka atap serta dinding dari gudang atag ini semuanya terbuat dari material bambu yang diikat dengan kawat. Kemudian untuk material pondasi menggunakan beton.

\section{Bambu}

Adapun alasan dan kelebihan dari penggunaan material bambu untuk kolom dan rangka gudang ini adalah sebagai berikut.

- Bambu tergolong material yang ekologis dimana material bambu aman bagi kesehatan manusia dan lingkungan; merupakan material lokal dan tersedia dalam jumlah banyak di alam; dapat didaur ulang; menghasilkan sedikit material waste.

- Dalam aspek kompresi/tekan bambu memiliki kekuatan lebih dari material beton (Suriani, 2017).

- Dalam aspek ketegangan/kekakuan bambu memiliki kekuatan yang sama bahkan lebih tinggi dari material baja (Suriani,2017).

- Bambu memiliki sifat yang elastis sehingga tahan terhadap angin ataupun gempa.

- Bambu memiliki harga yang cukup ekonomis apabila dibandingkan dengan material sejenis lainnya.

- Struktur dan rangka bambu bisa dengan mudah dibongkar apabila diperlukan mengingat gudang atag merupakan bangunan yang bersifat tidak permanen.

- Penanaman bambu selain mudah juga membawa dampak positif bagi lingkungan karena disebut lebih efisien dalam menyerap karbon dioksida dibandingkan dengan pohon biasa serta menghasilkan lebih banyak oksigen.

- Ringan, material bambu yang ringan mempermudah pembangunan gudang atag yang dalam proses pengerjaannya bergantung sepenuhnya pada tenaga manusia. 


\section{Di|sisteror}

Vol. 6, No. 2, Desember 2021, pISSN 2527-2853, eISSN 2549-2985
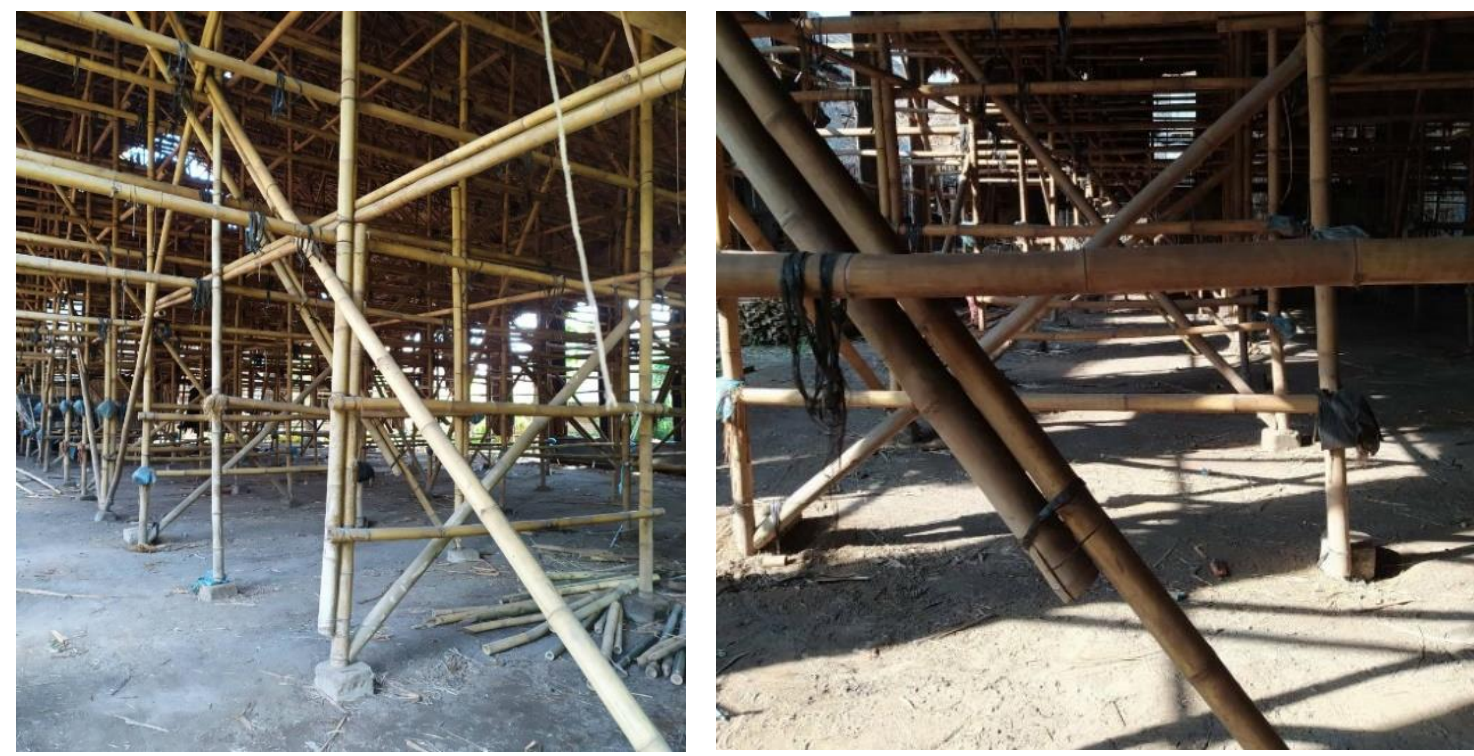

Gambar 7. Struktur kolom Gudang Atag

Sumber : Dokumentasi Penulis (2021)

Material bambu selain memiliki banyak kelebihan namun juga memiliki beberapa kekurangan sebagai berikut.

- Material bambu memiliki sensitifitas yang tinggi dengan air dan kelembaban (Bui et al, 2017). Kadar air yang tinggi pada bambu dapat mengakibatkan penurunan kekuatan dan pelapukan.

- Bambu rentan terhadap rayap, jamur, dan kumbang bubuk (Sulistyowati, 1996).

- Mudah terbakar.

Kelemahan dari material bambu pada poin satu dan dua sangat beresiko mengingat pada observasi lapangan yang telah dilakukan dapat ditemui beberapa struktur kolom bambu yang bersentuhan langsung dengan tanah walau sebagian besar dibatasi dengan pondasi beton. Poripori bambu yang bersentuhan langsung dengan tanah akan menyerap air dari tanah dan menyebabkan kelapukan. Rangka dinding dan atap dari gudang atag yang terbuat dari rangkaian bambu juga beresiko mengalami kerusakan seperti deskripsi diatas karena terpapar langsung dengan cuaca (hujan dan terik matahari). Walau begitu kedua poin kekurangan dari material bambu yang telah disebutkan pada poin satu dan dua dapat diatasi dengan proses pengawetan yang baik. Tanpa proses pengawetan yang baik apabila dihadapkan pada kondisi lembab dan cuaca ekstrim maka bambu hanya akan bertahan selama 1 - 3 tahun saja (Suriani, 2017). Namun proses pengawetan ini tentunya akan memakan biaya lebih.

\section{Pondasi Beton}

Pondasi gudang atag terbuat dari beton. Selain berfungsi untuk menahan beban dari struktur bambu agar tidak melesak ke dalam tanah, pondasi beton tersebut juga berfungsi sebagai tumpuan dari struktur bambu untuk mencegah agar air dari tanah tidak masuk ke dalam pori-pori struktur bambu. 


\section{Material Lantai}

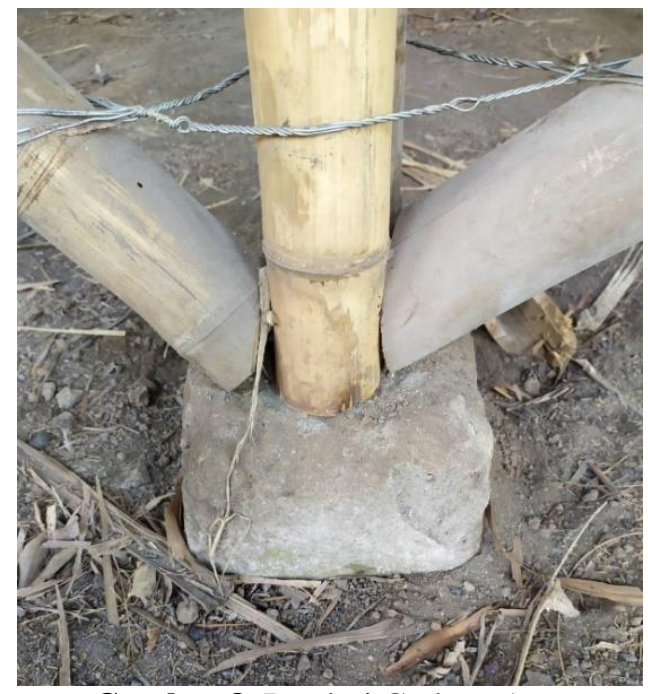

Gambar 8. Pondasi Gudang Atag

Sumber: Dokumentasi Penulis (2021)

Lantai gudang atag terbuat dari tanah yang dipadatkan. Alasan digunakannya material tanah antara lain karena: lantai tanah dapat berperan sebagai alat pendingin ruang karena bersifat menyerap dingin; tidak memakan biaya yang besar; perawatannya mudah.

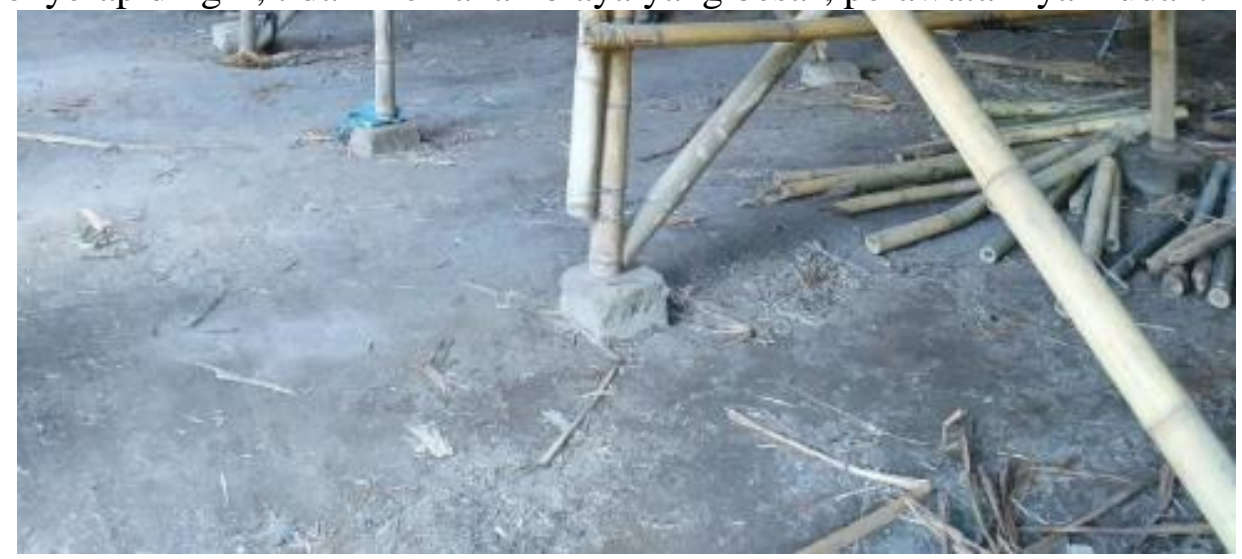

Gambar 9. Lantai tanah Gudang Atag

Sumber: Dokumentasi Penulis (2021)

\section{KESIMPULAN}

Melalui pembahasan yang ada dapat disimpulkan bahwa kriteria pemilihan material pembentuk gudang atag yakni material yang mendukung sistem pengovenan tembakau (dapat mempertahankan suhu, kelembaban, dan kecepatan angin yang stabil dan ideal didalam gudang) agar dapat menghasilkan tembakau berkualitas baik; material yang mudah ditemukan di wilayah sekitar dengan harga ekonomis, biaya pemeliharaan kecil, dan mudah di renovasi apabila terjadi kerusakan.

Material-material pembentuk gudang atag di desa Karanganyar kabupaten Jember ini memiliki kelebihan dan kekurangannya masing-masing. Material-material tersebut masih digunakan hingga saat ini karena kelebihan yang ditawarkan lebih banyak jika dibandingkan dengan kekurangannya. Hingga penelitian ini dilaksanakan masih belum ditemukan material alternatif yang lebih unggul untuk menggantikan material yang menjadi standar saat ini. Beberapa percobaan yang telah dilaksanakan dengan upaya untuk mengganti material gudang atag saat ini belum membuahkan hasil yang dikehendaki. Selain itu perubahan ke material yang 
lebih kokoh, tahan lama, dan modern akan berpotensi mengurangi vernakularitas dan nilai ekologi dari gudang atag.

Penelitian ini diharapkan dapat menjadi acuan untuk penelitian-penelitian yang akan datang berkenaan dengan material alternatif yang lebih unggul dan aman.

\section{DAFTAR PUSTAKA}

Artiningsih, N. K. A. (2012). Pemanfaatan Bambu pada Konstruksi Bangunan Berdampak Positif Bagi Lingkungan. METANA, 8(01). https://doi.org/10.14710/metana.v8i01.5117

Bui, Q.-B., Grillet, A.-C., \& Tran, H.-D. (2017). A Bamboo Treatment Procedure: Effects on the Durability and Mechanical Performance. Sustainability, 9(9), 1444.

Citraningrum, Andika dan Herawati, Daning. (2019). Lesson from Vernacular Tobacco Barn: A Passive Design Strategy for Energy-Independent Building.

Dhewayani, Jeanny dan Christianto, Eddy. (2006). Los, the tobacco drying barns in Klaten Regency (Central Java) A preliminary study of local folk architecture adaptation. INTA Conference 2006 - Proceedings: Harmony in Culture and Nature. Yogyakarta: Department of Architecture, Duta Wacana Christian University.

Gulo, W, Yovita Hardiwati (Ed). (2002). Metode Penelitian. Jakarta : PT Grasindo.

I Made Wirartha. (2006). Pedoman Penulisan Usulan Penelitian, Skripsi dan Tesis. Yogyakarta: Andi.

Indonesia.go.id. (2018, 21 September). Tembakau, Sejarah dan Cita Rasa Indonesia. Diakses pada 2 April 2021, dari https://indonesia.go.id/ragam/komoditas/ekonomi/tembakau-sejarah-dancita-rasa-indonesia.

Indonesia.go.id. (2019, 28 November). Tembakau Cerutu Jember, Emas Hijau yang Tetap Perkasa. Diakses pada 2 April 2021, dari https://indonesia.go.id/ragam/komoditas/ekonomi/tembakau-cerutu-jember-emas-hijauyang-tetap-perkasa.

Lembagatembakaujember.disperindag.jatimprov.go.id. (2016, 10 November). Melihat Sejarah Tembakau di Jember. Diakses pada 2 April 2021, dari https://lembagatembakaujember.disperindag.jatimprov.go.id/2016/11/10/melihat-sejarahtembakau-di-jemberl.

Moleong, Lexy J. (2007). Metodologi Penelitian Kualitatif. Edisi Revisi. Bandung : PT Remaja Rosdakarya.

Mulyana, Dedy. (2004). Metodologi Penelitian Kualitatif. Bandung: PT Remaja Rosdakarya.

Nugrahani, Farida. (2014). Metode Penelitian Kualitatif dalam Penelitian Pendidikan Bahasa. Solo: Cakra Books

Padmo, Soegijanto. (1994). The cultivation of Vorstenlands tobacco in Surakarta Residency and Besuki tobacco in Besuki Residency and its impact on the peasant economy and society: 1860-1960. Yogyakarta: Aditya Media.

Saraswati, T. (2013). Perlunya Penutup Atap Straw pada Bangunan Vernakular Masa Kini. Seminar Nasional : Stone, Steel, and Straw Building Materials and Sustainable Environment (hal. 291-299). Yogyakarta : Universitas Atma Jaya. 
Chen Ie Chin

Analisa Pemilihan Material pada Bangunan Gudang Atag di Desa Karanganyar Kabupaten Jember

Saraswati, T. (2008). Vernakularitas Los, Bangunan Pengering Tembakau di Kabupaten Klaten Jawa Tengah. Dimensi Teknik Arsitektur Vol. 36, No. 1, 65-74.

Sulistyowati, C. A. (1997). Pengawetan Bambu. Teknologi Wacana. Pusat Informasi Teknologi Terapan ELSPPAT. Jakarta, 6, 11-13.

Suriani, Efa. (2017). Bambu Sebagai Alternatif Penerapan Material Ekologis: Potensi dan Tantangannya. EMARA Indonesian Journal of Architecture, 3(1), 33-42. 